\title{
Effects of Metformin on Pregnancy Outcomes in Women with Polycystic Ovary Syndrome during First Trimester
}

\author{
Azza Abdel Mageid Abdelhameid, Khaled Fathy Helal, Mohamed Fathy Abohashem, \\ Mohamed Abdel-Moneim Al Minshawy* \\ Department of Obstetrics and Gynecology, Faculty of Medicine, Zagazig University, Egypt. \\ *Correspondence to: Mohamed Abdel-Moneim Al Minshawy, E-mail: M.almeshawy@gmail.com, \\ Mobile: +200122057212
}

\begin{abstract}
Background: Polycystic ovary syndrome is a hormonal disorder commonly found in women of reproductive age affecting about $15 \%$ of them and is considered the most common cause of anovulatory infertility. Administration of metformin to these anovulatory women increase ovulation rate and continuing in first trimester improves the pregnancy outcome.
\end{abstract}

Objective: To assess pregnancy outcome in women with polycystic ovary syndrome who continue metformin during first trimester with its co-morbidity and mortality.

Patients and Methods: This prospective intervention study was conducted on 44 pregnant polycystic ovary syndrome women who were attending for antenatal care at Outpatient Clinic, Obstetric and Gynaecological Department, Zagazig University Hospital. These 44 women took metformin before pregnancy and was followed up by indication of ovulation and metformin (1000-1500 mg/day) until they got pregnant. Then they were divided into two group: group 1 (22) continuous metformin dose during first trimester and group 2 (22) who discontinued metformin therapy once pregnancy diagnosed. The 2 groups followed up by fasting blood glucose and fasting serum insulin at their first visit and at 28 weeks of gestation.

Results: group 1 who continued (1000_1500mg /day) metformin in first trimester had good pregnancy outcomes (significantly lower weight gain, lower gastrointestinal diabetes mellitus and lower spontaneous miscarriage) than group 2 who discontinued metformin ( $\mathrm{p}$ value: 0.001 ).

Conclusions: good maternal outcomes in women with polycystic ovary syndrome who continued metformin during first trimester including decrease incidence of spontaneous miscarriage and gastrointestinal diabetes mellitus.

Key words: Polycystic ovary syndrome (PCOS), Metformin, spontaneous abortion.

\section{INTRODUCTION}

Polycystic ovary syndrome (PCOS) is a heterogeneous disorder affecting 6-15\% of women of reproductive age and it is considered as the most common cause of chronic anovulation and anovulatory infertility ${ }^{(1)}$. The Rotterdam (2003) PCO diagnostic criteria in adults considered that two of clinical or biochemical hyperandrogenism, ovulatory dysfunction, or polycystic ovaries on ultrasound are diagnostic ${ }^{(2)}$.

The threshold for poly cystic ovarian morphology (PCOM) should be on either ovary, a follicle number per ovary of $\geq 20$ and/or an ovarian volume $\geq 10 \mathrm{ml}$, ensuring no corpora lutea, cysts or dominant follicles are present. In patients with irregular menstrual cycles and hyperandrogenism, an ovarian ultrasound is not necessary for PCOS diagnosis. However, ultrasound will identify the complete PCOS phenotype in addition to poor conception rate. Early pregnancy loss rates are significantly higher $(20-40 \%)$ than in general population $^{(3)}$.

Many of these women require assisted reproductive techniques to conceive. In one metaanalysis and one controlled clinical study, the PCOSinduced effects on reproduction were shown to be limited not only to infertility, but also to include adverse pregnancy outcomes. The most commonly identified of those are gestational diabetes mellitus (GDM), early pregnancy loss, gestational hypertension, pre-eclampsia and preterm delivery ${ }^{(4)}$.

Although the mechanism of early pregnancy loss is unclear. Several interrelated factors appear to increase the risk of spontaneous miscarriages including higher lutenizing hormone levels, obesity, hyperandrogenism and insulin resistance ${ }^{(5)}$. PCOs women are believed to be strongly associated with insulin resistance and compensatory hyperinsulinemia ${ }^{(\boldsymbol{\sigma})}$. Hyperinsulinemic insulin resistance is implicated as independent risk factor for early pregnancy loss as it plays a key role in the disorder by increasing androgen concentration and impeding ovulation leading to adverse effect on endometrial function and implantation environment. Therefore, the abnormal endocrine environment might exert an influence on the endometrium. The ultimate cause of miscarriage could be secondary to endometrial non-receptivity ${ }^{(3)}$.

Administration of various insulin sensitizing drugs such as metformin has been shown to decrease serum androgen concentrations and to increase ovulation rates in affected women ${ }^{(7)}$. Continued metformin during pregnancy in women with PCOS improves pregnancy outcomes by decreasing spontaneous miscarriage rate and prevention of GDM 
with its co-morbidity and mortality ${ }^{(8)}$. The aim was to study the effect of continued metformin in the 1st trimester in pregnant women with PCOS and its effect on pregnancy outcome with its co-morbidity and mortality.

\section{PATIENTS AND METHODS}

This study was conducted on 44 pregnant PCO women who were attending for antenatal care at Outpatient Clinic at Obstetric and Gynecological Department of Zagazig University Hospitals. The selected patients were divided into 2 equal groups; group (I) included 22 pregnant women who continued metformin therapy during the first trimester with mean age of $28.05 \pm 2.44$ years and group (II) included 22 pregnant women with PCOs who discontinued metformin therapy during the first trimester with mean age of $28.14 \pm 2.09$ years. All cases had confirmed diagnosis of PCOS before pregnancy according to the revised 2003 Rotterdam criteria $^{(2)}$.

Inclusion criteria: Known PCO patient diagnosed according to 2003 Rotterdam criteria two of three. Oligo or anovulation. Hyperandrogenism. Poly cystic ovarian morphology ultrasonography in the absence of other diseases (these patients became pregnant while taking metformin). Intrauterine singleton pregnancy with positive pulsation.

Exclusion Criteria: Age < less than 18 years or more than 40 years. Pre-gestational diabetes mellitus. Hypertensive patient. Patients with liver, cardiac, renal, or endocrinal diseases. Patients with history of coagulation disorder. BMI more than $30 \mathrm{~kg} / \mathrm{m}^{2}$.

\section{Ethical approval:}

Written informed consent was obtained from all participants. The Research Ethics Committee of the Faculty of Medicine, Zagazig University approved the study. Study has been carried out on experiments involving human subjects in compliance with the Code of Ethics of the World Medical Association (Helsinki Declaration).

Full medical history were obtained from all selected women and they were subject to thorough medical and obstetrical examination. Routine laboratory investigations included urine analysis, complete blood counting (CBC) and kidney and liver functions. Blood pressure measurement and urine examination for presence of protein were done for selected women for detection of pregnancy induced hypertension $(\mathrm{PIH})$ including preeclampsia.

Cases in group 1 received metformin, starting in a dose of $1000 \mathrm{mg}$ daily increased to $2500 \mathrm{mg}$ daily according to body mass index (BMI) and response to treatment, some cases used other ovulation inducing drugs as clomiphene citrate and or gonadotrophines. When pregnancy occurred, cases continued on metformin in a dose of 1000-1500 mg daily till the end of pregnancy. Cases in group 2 got pregnant spontaneously or by use of ovulation-inducing agents but did not use metformin before or after pregnancy.

\section{Assessment of Glycemic Status and Insulin Resistance:}

Glycemic status of all selected pregnant women by measurement of fasting blood glucose "FBG" and fasting serum insulin levels, followed by calculation of HOMA IR (Homeostatic Model Assessment Of Insulin Resistance) was done at 8 weeks and repeated between 24 and 28 weeks. HOMA-IR index was calculated using this formula:

Fasting blood glucose $(\mathrm{mg} / \mathrm{dL}) \times$ fasting insulin level $(\mathrm{mU} / \mathrm{mL}) / 405$.

Detection of gestational diabetes mellitus (GDM) was done at 8 weeks pregnancy and repeated between 24 and 28 weeks. When negative, to be repeated lastly at 36 weeks by using oral glucose tolerance test (OGTT), which was based on $100 \mathrm{gm}$ glucose tolerance. The limiting glucose levels were 95, 180, and $155 \mathrm{mg} / \mathrm{dl}$ for fasting, 1 and $2 \mathrm{~h}$, respectively. When one value was above the limit, it was considered impaired glucose tolerance (IGT), and when two values were above the limit, it was considered as GDM.

Fetal outcomes were measured and recorded including the rate of; spontaneous miscarriage (fetal loss before 24 weeks). Prematurity (delivery before completed 36 weeks), fetal macrosomia (fetal weight more than $4.5 \mathrm{~kg}$ ), intrauterine growth restriction (IUGR) (fetal abdominal circumference less than 5th percentile for GA), suspected fetal asphyxia at birth (5 min Apgar score $\leq 7$ ) and recording of congenital malformation and neonatal mortality.

\section{Statistical Analysis}

Student's t test, SD and Chi-square test (X2) were used to assess the statistical significance when appropriate, two-tailed value of $\mathrm{P} \leq 0.05$ was considered statistically significant; The SPSS version 20.0 (SPSS Inc, Chicago, IL, 2001) statistical package was used to analyze data.

\section{RESULTS}

Initially 48 cases were recruited for the study but 4 cases were excluded (one case stopped metformin early and 3 cases missed follow up) so finally 44 cases were included in the study group and classified to Group I: continued metformin till 14 weeks gestation, Group II: stop metformin once pregnancy diagnosed.

This study showed that there was no significant difference between the studied groups as regards maternal age, body mass index "BMI", gestational age at start of study and presence of previous infertility (table 1).

There was no statistical significant difference between studied groups as regard systolic and diastolic blood pressure and proteinuria (table 2). 
This study showed that there was no statistical significant difference between both studied groups regarding fasting blood glucose, fasting serum inulin and HOMA-IR (table 3 ).

Table (4) showed that the women in group (I) had significantly lower fasting blood glucose, fasting serum insulin and HOMA-IR index in comparison with those in group (II).

This study showed that women who continued metformin therapy during first trimester had significantly lower weight gain, lower incidence of
GDM, lower need for insulin therapy and lower incidence of spontaneous abortion and insignificantly lower incidence of PIH in comparison with women who discontinued metformin (Figure 1,2).

Table (5) showed that the women who continued metformin therapy during first trimester had insignificantly lower preterm delivery, macrosomia, IUGR, fetal asphyxia (Apgar score $\leq 7$ ) and congenital anomalies in comparison with women who discontinue metformin.

Table (1): Demographic and anthropometric data of the studied groups

\begin{tabular}{|c|c|c|c|c|}
\hline Variable & $\begin{array}{c}\text { Metformin } \\
\text { Group } \\
\mathbf{N}=\mathbf{2 2}\end{array}$ & $\begin{array}{c}\text { No metformin } \\
\text { Group } \\
\mathbf{N}=\mathbf{2 2}\end{array}$ & $\begin{array}{c}\text { t- } \\
\text { value }\end{array}$ & $\begin{array}{c}\text { p- } \\
\text { value }\end{array}$ \\
\hline $\begin{array}{l}\text { Maternal Age (year): } \\
\text { - Mean } \pm \text { SD } \\
\text { - range }\end{array}$ & $\begin{array}{c}28.05 \pm 2.44 \\
24-33\end{array}$ & $\begin{array}{c}29.14 \pm 2.09 \\
25-32\end{array}$ & 2.922 & 0.095 \\
\hline $\begin{array}{l}\text { Maternal BMI: } \\
\text { - Mean } \pm \text { SD } \\
\text { - range }\end{array}$ & $\begin{array}{c}27.97 \pm 0.9 \\
26-29\end{array}$ & $\begin{array}{c}28.44 \pm 0.63 \\
27-29\end{array}$ & 4.027 & 0.051 \\
\hline $\begin{array}{l}\text { Gestational age at start of study } \\
\text { (weeks) } \\
\quad-\text { Mean } \pm \text { SD } \\
\end{array}$ & $5.5 \pm 0.9$ & $5.8 \pm 0.63$ & 1.2 & 0.7 \\
\hline $\begin{array}{l}\text { Previous infertility } \\
\text { - 1ry infertility } \\
\text { - 2ry infertility }\end{array}$ & $\begin{array}{c}19(86.4 \%) \\
3(13.6 \%)\end{array}$ & $\begin{array}{c}18(81.6 \%) \\
4(18.4 \%)\end{array}$ & $\begin{array}{c}X^{2} \\
0.169\end{array}$ & 0.680 \\
\hline
\end{tabular}

Table (2): Initial clinical assessment of the studied groups

\begin{tabular}{|c|c|c|c|c|}
\hline Variable & $\begin{array}{l}\text { Metformin } \\
\text { Group } \\
\mathbf{N}=\mathbf{2 2}\end{array}$ & $\begin{array}{l}\text { No metformin } \\
\text { Group } \\
\mathbf{N}=\mathbf{2 2}\end{array}$ & $\begin{array}{c}\text { t- } \\
\text { value }\end{array}$ & $\begin{array}{c}\text { p- } \\
\text { value }\end{array}$ \\
\hline $\begin{array}{l}\text { Systolic B.P.: }(\mathbf{m m} / \mathbf{H g}) \\
- \text { Mean } \pm \text { SD } \\
- \text { range }\end{array}$ & $\begin{array}{c}111.82 \pm 6.82 \\
100-125\end{array}$ & $\begin{array}{c}112.5 \pm 7.68 \\
100-125\end{array}$ & 0.104 & 0.748 \\
\hline $\begin{array}{l}\text { Diastolic B.P.: }(\mathbf{m m} / \mathbf{H g}) \\
- \text { Mean } \pm \text { SD } \\
- \text { range }\end{array}$ & $\begin{array}{c}71.36 \pm 6.76 \\
60-80\end{array}$ & $\begin{array}{c}72.59 \pm 7.14 \\
60-85\end{array}$ & 0.343 & 0.561 \\
\hline $\begin{array}{l}\text { Proteinuria: } \\
\text { - Yes } \\
\text { - No }\end{array}$ & $\begin{array}{c}1 \\
21\end{array}$ & $\begin{array}{c}3 \\
19\end{array}$ & $\begin{array}{l}X^{2} \\
1.1\end{array}$ & 0.294 \\
\hline
\end{tabular}

Table (3): Glycemic status assessment of the studied groups at 8 weeks

\begin{tabular}{|l|c|c|c|c|}
\hline \multicolumn{1}{|c|}{ Variable } & $\begin{array}{c}\text { Metformin } \\
\text { Group }\end{array}$ & $\begin{array}{c}\text { No metformin } \\
\text { Group }\end{array}$ & $\begin{array}{c}\text { t- } \\
\text { value }\end{array}$ & $\begin{array}{c}\text { p- } \\
\text { value }\end{array}$ \\
\hline FBG: $(\mathbf{m g} / \mathbf{d l})$ & $100.05 \pm 2.72$ & $101.32 \pm 3.06$ & 2.117 & 0.153 \\
- Mean \pm SD & $97-108$ & $97-109$ & \\
- range & $20.23 \pm 2.14$ & $21.5 \pm 2.04$ & 2.247 & 0.141 \\
\hline F Insulin: (uIU/ml) & $14-25$ & $18-26$ & & \\
- Mean \pm SD & & & & \\
- range & $5.00 \pm 0.58$ & $5.38 \pm 0.53$ & 3.335 & 0.075 \\
\hline HOMA IR: & $3.35-6.13$ & $4.44-6.42$ & & \\
- Mean \pm SD & range & & & \\
\hline
\end{tabular}

HOMA IR (Homeostatic Model Assessment of Insulin Resistance) 
Table (4): Glycemic status assessment of the studied groups at 24-28 weeks

\begin{tabular}{|l|c|c|c|c|}
\hline Variable & $\begin{array}{c}\text { Metformin } \\
\text { Group }\end{array}$ & $\begin{array}{c}\text { No metformin } \\
\text { Group }\end{array}$ & $\begin{array}{c}\text { t- } \\
\text { value }\end{array}$ & p-value \\
\hline $\begin{array}{l}\text { FBG (mg/dl): } \\
\text { Mean } \pm \text { SD }\end{array}$ & $\begin{array}{c}115.7 \pm 7.1 \\
90-136\end{array}$ & $\begin{array}{c}144.95 \pm 9.65 \\
95-165\end{array}$ & 14.6 & $<0.001^{* *}$ \\
- range & $17.09 \pm 2.00$ & $20.95 \pm 3.7$ & 18.530 & $<0.001^{* *}$ \\
\hline F Insulin: (uIU/ml) & $14-20$ & $15-27$ & & \\
- Mean \pm SD & $4.9 \pm 0.49$ & $7.5 \pm 1.17$ & 23.464 & $<0.001^{* *}$ \\
- range & $3.0-5.0$ & $3.3-7.64$ & & \\
\hline HOMA IR: & & & \\
Mean \pm SD & range & &
\end{tabular}

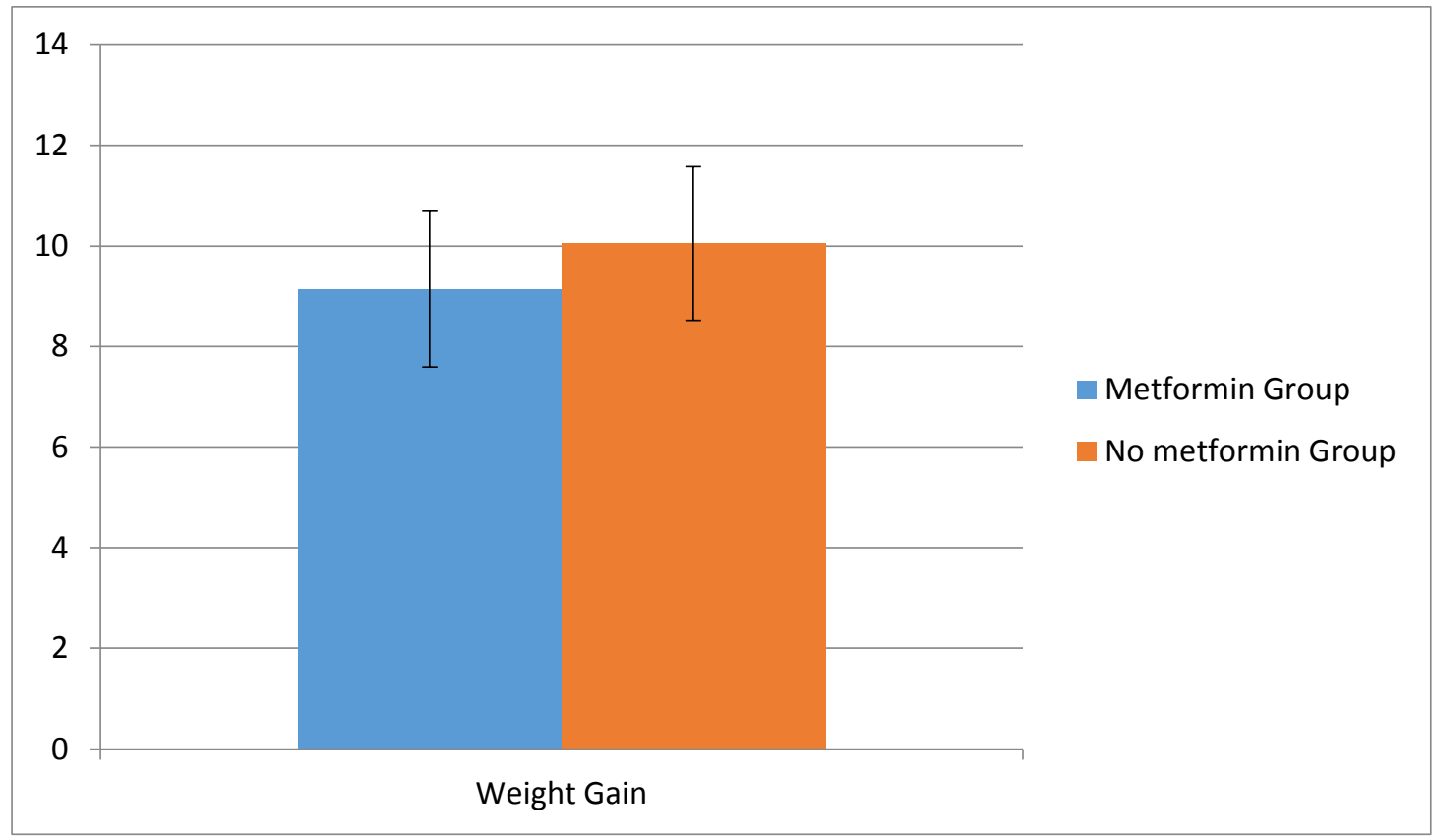

Figure (1): Distribution of weight gained during pregnancy among the studied groups

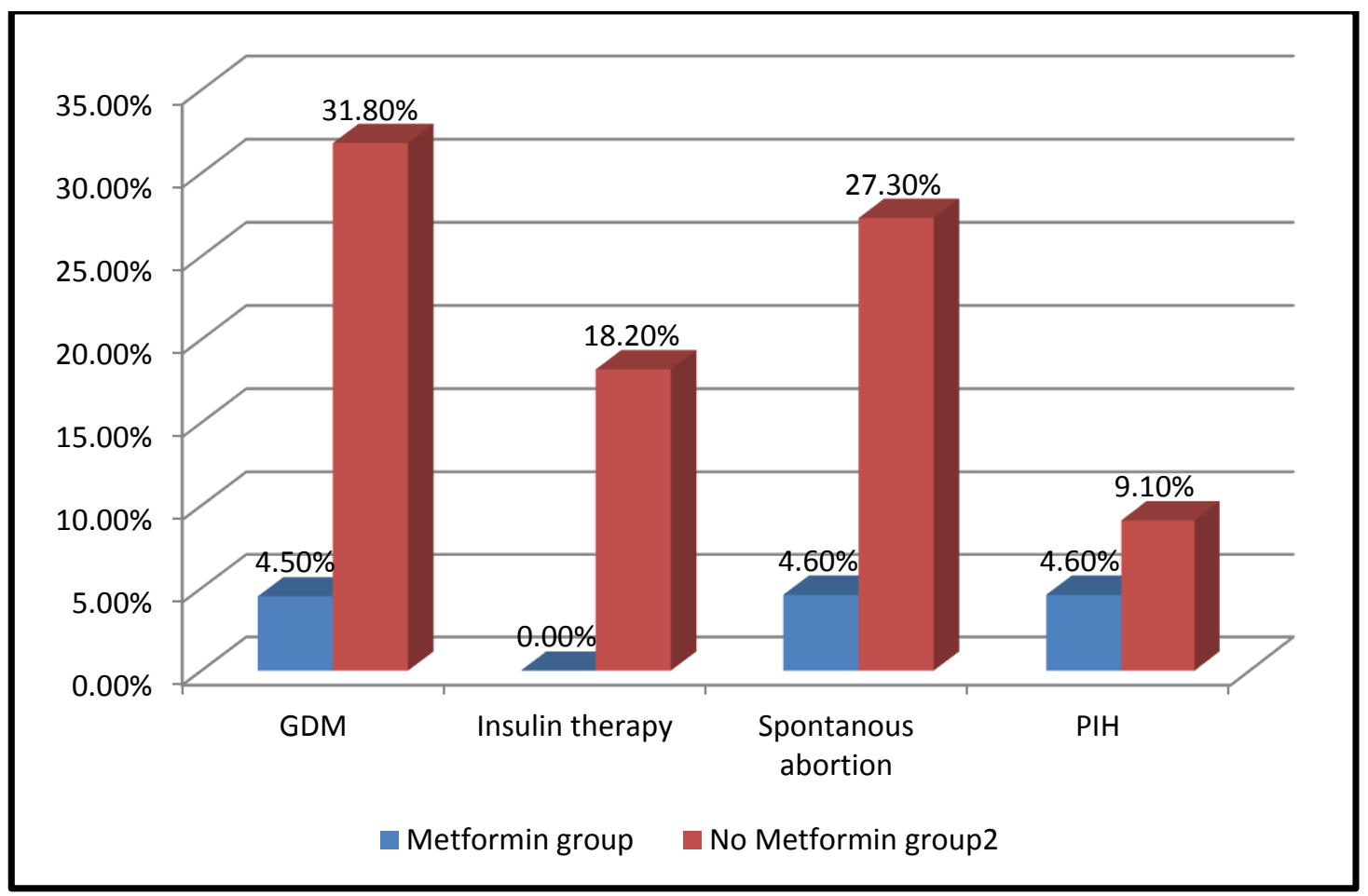

Figure (2): Maternal outcome among studied groups 
Table (5): Neonatal outcome of the studied groups

\begin{tabular}{|c|c|c|c|c|}
\hline Variable & $\begin{array}{l}\text { Metformin } \\
\text { Group }\end{array}$ & $\begin{array}{c}\text { No metformin } \\
\text { Group }\end{array}$ & $X^{2}$ & $\begin{array}{c}\text { p- } \\
\text { value }\end{array}$ \\
\hline $\begin{array}{l}\text { Prematurity: } \\
\text { - Yes } \\
\text { - No }\end{array}$ & $\begin{array}{c}1(4.6 \%) \\
21(95.4 \%)\end{array}$ & $\begin{array}{c}1(4.6 \%) \\
21(95.4 \%)\end{array}$ & 0.0 & 1.0 \\
\hline $\begin{array}{l}\text { Macrosomia: } \\
\text { - Yes } \\
\text { - No }\end{array}$ & $\begin{array}{c}1(4.6 \%) \\
21(95.4 \%)\end{array}$ & $\begin{array}{c}2(9.1 \%) \\
20(90.9 \%)\end{array}$ & 0.358 & 0.549 \\
\hline $\begin{array}{l}\text { IUGR: } \\
\text { - Yes } \\
\text { - No } \\
\end{array}$ & $\begin{array}{c}1(4.6 \%) \\
21(95.4 \%)\end{array}$ & $\begin{array}{c}1(4.6 \%) \\
21(95.4 \%)\end{array}$ & 0.0 & 1.0 \\
\hline $\begin{array}{l}\text { APGAR at } 5 \min \leq 7: \\
\text { - Yes } \\
\text { - No }\end{array}$ & $\begin{array}{c}1(4.6 \%) \\
21(95.4 \%)\end{array}$ & $\begin{array}{c}2(9.1 \%) \\
20(90.9 \%)\end{array}$ & 0.358 & 0.549 \\
\hline $\begin{array}{l}\text { Anomalies: } \\
\text { - Yes } \\
\text { - No }\end{array}$ & $\begin{array}{c}0(0.0 \%) \\
21(100.0 \%)\end{array}$ & $\begin{array}{c}1(4.6 \%) \\
21(95.4 \%)\end{array}$ & 1.023 & 0.314 \\
\hline
\end{tabular}

\section{DISCUSSION}

This study showed that there was no significant data between both groups of the study as regards age, $\mathrm{BMI}$, blood pressure, $\mathrm{CBC}$, fasting glucose, and fasting insulin. This is in agreement with Abd El Hameed et al. ${ }^{(8)}$ who reported in their study that there was no significant difference between the studied groups at baseline visit as regards age, BMI, fasting insulin, fasting glucose and HOMA IR index.

At 24 weeks of gestation, our results showed that the pregnant women who continued metformin therapy in group (I) had significantly lower fasting blood level, fasting serum insulin level and HOMAIR index in comparison with those who stopped metformin therapy in group (II) (p-value <0.001). These findings are in agreement with Abd El Hameed et al. ${ }^{(8)}$ who reported that women who continued metformin therapy during pregnancy were having significant lower values for fasting glucose, fasting insulin, and HOMA IR in comparison with those who conceived without taking metformin and did not take it during pregnancy.

Regarding weight gain, lesser weight gain during pregnancy was observed in women in group (I) in comparison with those in group (II) $(9.14 \pm$ 1.55 vs $10.05 \pm 1.53$ ) with p-value: 0.001 . Stanford et al. ${ }^{(9)}$ reported in their study on 450 nondiabetic severely obese (BMI > $35 \mathrm{~kg} / \mathrm{m} 2$ ) mixed ethnicity women that metformin was associated with less maternal gestational weight gain $(\mathrm{kg})$ (median: 4.6 vs. $6.3 ; \mathrm{p}<0.01$ ) compared to the placebo. Hyer $\boldsymbol{e t}$ al. ${ }^{(10)}$ reported in their review about the metformin in gestational diabetes that maternal gestational weight gain $(\mathrm{kg})$ was significantly reduced in the metformin group $(3.9 \pm 4.6$ vs. $7 \pm 4.5$, p: 0.003$)$.

Regarding gestational diabetes mellitus (GDM), our results showed that women who didn't take metformin in group (II) had 7-fold higher incidence of GDM in comparison with those who continued metformin therapy in group (I) $(31.8 \%)$ vs $4.5 \%$ ) with p-value: 0.01 . There was a significant difference between both groups regarding the need for insulin therapy to achieve good control of gestational diabetes mellitus with p-value: 0.036. This finding is in agreement with Ainuddin et al. ${ }^{(11)}$ who reported that a total of $1(4.6 \%)$ patients in metformin group developed GDM while 9 (40.9\%, $0.004)$ developed GDM in no metformin group. Patients not receiving metformin were 4 times likely to have GDM compared to those who received it. Also, Abd El Hameed et al. ${ }^{(8)}$ reported in their study that the incidence of GDM in cases who received metformin during pregnancy was significantly lower than cases who did not receive it (3.2\% versus $23.08 \%$, respectively). In the study done by Glueck et al. (12), they found 10-fold reduction in the incidence of GDM and in another study done by Glueck et al. ${ }^{(13)}$ they found 5-fold reduction.

Regarding spontaneous miscarriage, our results showed that women in group (I) had significantly lower incidence of spontaneous miscarriage in comparison with those in group (II) with p-value: 0.04. This finding is in consistency with Abd El Hameed et al. ${ }^{(8)}$ who reported that the rate of spontaneous miscarriage in their study was significantly lower in cases who received metformin. Similar findings were reported by Jakubowicz et al. ${ }^{(14)}$ who reported in their retrospective study that metformin administration during pregnancy reduced the risk of pregnancy loss in the first trimester in women with PCOS. Moreover, Khattab et al. (15) suggested in their prospective study that administration of metformin throughout pregnancy to women with PCOS was associated with a marked reduction in the rate of early pregnancy loss (EPL). Also, Zeng et al. (16) reported in their meta-analysis that metformin 
helped to reduce the rates of EPL. While against our findings, Heard et al ${ }^{(17)}$ did not find that metformin reduces first trimester miscarriage.

This study showed that women in group (I) had insignificantly lower incidence of pregnancyinduced hypertension (PIH) in comparison with group (II) p-value: 0.549. This finding is in agreement with Abd El Hameed et al. ${ }^{\left({ }^{(8)}\right.}$ as they reported that PIH was less common in the metformin group in comparison with the non-metformin group but this was of no statistical significance. Also, Syngelaki et al. ${ }^{(18)}$ reported that the incidence of preeclampsia was lower in the metformin group than in the placebo group $(3.0 \%$ vs. $11.3 \%$; odds ratio, $0.24 ; 95 \%$ confidence interval, 0.10 to 0.61 ; $\mathrm{P}=0.001)$.

Regarding fetal outcomes, our results showed that there was no significant difference between the two studied groups as regarding incidence of preterm delivery, macrosomia, IUGR, APAGR score at 5 min, with $\mathrm{p}$-value $1.0,0.549,1.0,0.549,0.314$ respectively. These findings are in agreement with Abd El Hameed et al. ${ }^{(8)}$ and Begum et al. ${ }^{(19)}$ where the incidence of preterm birth, fetal macrosomia, IUGR, suspected fetal asphyxia at birth were lowered in group 1. However, it was of no statistical significance, but in disagreement with Nawaz et al. (20) who showed significant reduction of IUGR and preterm birth in the metformin-treated group and this may be due to the small number of cases in this study compared with those of Nawaz et al. (20) whom carried their study on 137 cases.

There is accumulated evidence about the safety of use of metformin throughout pregnancy, but evidence of increased risk of congenital abnormalities has ever been reported (21). A retrospective study done by Diamanti-Kandarakis et al. ${ }^{(22)}$ had examined the perinatal outcomes in metformin-treated and control pregnancies, and found that the rates of neonatal growth deficits, congenital defects, and neonatal unit admission were either comparable in both groups or less common in the metformin-treated group. Gilbert et al. ${ }^{(23)}$ also believed that there was no evidence of an increased risk of major malformations when metformin was taken during the first trimester. Metformin started before pregnancy and continued until term in women with PCOS has benefits both for the mother (reducing GDM, gestational hypertension, preterm labour) and the developing foetus (reducing early pregnancy loss, foetal growth retardation). The largely unanswered question is the long-term impact of intrauterine metformin exposure on childhood development. The MiG TOFU results at 9 years could be interpreted as showing a neutral effect as body fat, visceral adipose tissue, and liver fat were similar in metformin and insulin groups. Conversely the unexpected finding of increased body mass index in the metformin offspring might indicate an increased risk of childhood obesity. The low followup rate, however, makes the results difficult to interpret. On-going long-term follow-up studies starting from the offspring of mothers in the obesity trials will help answer this current uncertainty ${ }^{(\mathbf{1 0})}$.

\section{CONCLUSIONS}

Continuing of metformin therapy during 1st trimester pregnancy in women with PCOS was associated with good maternal outcomes including decreased incidence of spontaneous miscarriage and gestational DM. In addition, it was associated with slight but insignificantly improvement in fetal outcome.

\section{REFERENCES}

1. Hunter M, Sterrett J (2000): Polycystic Ovary Syndrome: It's Not Just Infertility. Am Fam Physician, 62 (5): 1079-88.

2. Rotterdam ESHRE/ASRM-Sponsored PCOS Consensus Workshop Group (2004): Revised 2003 consensus on diagnostic criteria and long-term health risks related to polycystic ovary syndrome. Fertil Steril., 81 (1): 19-25.

3. Al-Biate M (2015): Effect of metformin on early pregnancy loss in women with polycystic ovary syndrome. Taiwanese Journal of Obstetrics and Gynecology, 54 (3): 266-9.

4. Ghazeeri G, Nassar A, Younes $Z$ et al. (2012): Pregnancy outcomes and the effect of metformin treatment in women with polycystic ovary syndrome: an overview. Acta Obstet Gynecol Scand., 91 (6): 65878.

5. Allahbadia G, Merchant R (2011): Polycystic ovary syndrome and impact on health. Middle East Fertility Society Journal, 16 (1): 19-37.

6. Diamanti-Kandarakis E, Dunaif A (2012): Insulin Resistance and the Polycystic Ovary Syndrome Revisited: An Update on Mechanisms and Implications. Endocr Rev., 33 (6): 981-1030.

7. Sangraula H, Paudel K, Sharma M (2009): Metformin and troglitazone in the treatment of female infertility associated with polycystic ovarian syndrome. JNMA J Nepal Med Assoc., 48 (176): 3359.

8. Abd El Hameed A, Shreif H, Mowafy H (2011): The role of continuing metformin therapy during pregnancy in the reduction of gestational diabetes and improving pregnancy outcomes in women with polycystic ovary syndrome. Middle East Fertility Society Journal, 16 (3): 204-8.

9. Stanford F, Alfaris N, Misra M (2016): Metformin versus Placebo in Obese Pregnant Women without Diabetes Mellitus. N Engl J Med., 374: 434-43.

10. Hyer S, Balani J, Shehata $H$ (2018): Metformin in Pregnancy: Mechanisms and Clinical Applications. Int J Mol Sci., 19 (7): 1954.

11. Ainuddin J, Kazi S, Aftab S et al. (2015): Metformin for preventing gestational diabetes in women with polycystic ovarian syndrome. J Coll Physicians Surg Pak., 25 (4): 237-41. 
12. Glueck $C$, Wang $P$, Kobayashi $S$ et al. (2002): Metformin therapy throughout pregnancy reduces the development of gestational diabetes in women with polycystic ovary syndrome. Fertil Steril., 77 (3): 5205.

13. Glueck C, Pranikoff J, Aregawi D et al. (2008): Prevention of gestational diabetes by metformin plus diet in patients with polycystic ovary syndrome. Fertil Steril., 89 (3): 625-34.

14. Jakubowicz $\mathrm{D}$, Iuorno $\mathrm{M}$, Jakubowicz $\mathrm{S}$ et al. (2002): Effects of metformin on early pregnancy loss in the polycystic ovary syndrome. J Clin Endocrinol Metab., 87 (2): 524-9.

15. Khattab S, Mohsen I, Foutouh I et al. (2006): Metformin reduces abortion in pregnant women with polycystic ovary syndrome. Gynecol Endocrinol., 22 (12): 680-4.

16. Zeng $X$, Zhang Y, Tian $Q$ et al. (2016): Effects of metformin on pregnancy outcomes in women with polycystic ovary syndrome: A meta-analysis. Medicine (Baltimore), 36: 4526-33.

17. Heard M, Pierce A, Carson S et al. (2002): Pregnancies following use of metformin for ovulation induction in patients with polycystic ovary syndrome. Fertility and Sterility, 77 (4): 669-73.

18. Syngelaki A, Nicolaides K, Balani J et al. (2016): Metformin versus Placebo in Obese Pregnant Women without Diabetes Mellitus. N Engl J Med., 374(5): 434-43.
19. Begum M, Khanam N, Quadir E et al. (2009): Prevention of gestational diabetes mellitus by continuing metformin therapy throughout pregnancy in women with polycystic ovary syndrome. J Obstet Gynaecol Res., 35 (2): 282-6.

20. Nawaz F, Khalid R, Naru T et al. (2008): Does continuous use of metformin throughout pregnancy improve pregnancy outcomes in women with polycystic ovarian syndrome? J Obstet Gynaecol Res., 34 (5): 832-7.

21. Glueck C, Goldenberg N, Wang P et al. (2004): Metformin during pregnancy reduces insulin, insulin resistance, insulin secretion, weight, testosterone and development of gestational diabetes: prospective longitudinal assessment of women with polycystic ovary syndrome from preconception throughout pregnancy. Hum Reprod (Oxford, England), 19: 510 21.

22. Diamanti-Kandarakis E, Christakou C, Kandaraki E et al. (2010): Metformin: an old medication of new fashion: evolving new molecular mechanisms and clinical implications in polycystic ovary syndrome. Eur J Endocrinol., 162 (2): 193-212.

23. Gilbert C, Valois M, Koren G (2006): Pregnancy outcome after first-trimester exposure to metformin: a meta-analysis. Fertil Steril., 86 (3): 658-63. 